\title{
Antiangiogenic Therapy in Pancreatic Neuroendocrine Tumors
}

\author{
MONICA CAPOZZI ${ }^{1}$, CLAUDIA VON ARX ${ }^{2}$, CHIARA DE DIVITIIS ${ }^{1}$, ALESSANDRO OTTAIANO $^{1}$, \\ FABIANA TATANGELO ${ }^{3}$, GIOVANNI MARIA ROMANO ${ }^{4}$ and SALVATORE TAFUTO ${ }^{1}$ \\ (On behalf of ENETS Center of Excellence Multidisciplinary Group for Neuroendocrine Tumors in Naples, Italy) \\ ${ }^{1}$ Department of Abdominal Oncology, Division of Medical Oncology, \\ National Cancer Institute IRCCS “G. Pascale Foundation", Naples, Italy; \\ ${ }^{2}$ Department of Clinical Medicine and Surgery, University Federico II of Naples, Naples, Italy; \\ ${ }^{3}$ Department of Diagnostic Pathology and Laboratory, \\ National Cancer Institute IRCCS “G. Pascale Foundation”, Naples, Italy; \\ ${ }^{4}$ Department of Abdominal Oncology, Division of Surgical Oncology, \\ National Cancer Institute IRCCS “G. Pascale Foundation”, Naples, Italy
}

\begin{abstract}
In recent years, many progresses have been pursued in the management of advanced pancreatic neuroendocrine tumor (pNET); most of them were prompted by increasing knowledge of biology of these neoplasms, including the identification of promising biological targets for therapy. PNETS belong to a group of rare neoplastic diseases. They originate from neuroendocrine system cells and are very heterogeneous regarding anatomic localization and aggressiveness. Recently, many efforts have been particularly focused on the identification of pathologic pathways and innovative drugs in order to treat patients with unresectable, metastatic disease, in progressive well-differentiated pNETs. Chemotherapy remains the mainstay of treatment of poorly-differentiated pNETs. The positive results obtained by sunitinib, a multi-targeted tyrosine kinase receptor inhibitor of vascular endothelial growth factor receptor (VEGFR) 1-3, platelet-derived growth factor receptor (PDGFR), c-kit, RET, colony stimulating factor-1 receptor $(C S F-1 R)$ and Fms-like tyrosine kinase 3 (FLT3), with direct antitumor and antiangiogenic effects, have highlighted the importance of tumor angiogenesis inhibition in controlling these tumors. Angiogenesis is a crucial process during tumor progression and plays a key role in development of metastasis.
\end{abstract}

This article is freely accessible online.

Correspondence to: Dr. Monica Capozzi, Istituto Nazionale Tumori di Napoli, "G. Pascale Foundation", Department of Abdominal Oncology, via M. Semmola, 80131, Naples, Italy. Tel: +39 0815903680,e-mail: m.capozzi@ istitutotumori.na.it

Key Words: Neuroendocrine tumors, angiogenesis, sunitinib, bevacizumab, review.
The role of angiogenesis in the malignant spread of pNET cells is finally supported by in vivo studies conducted on the RIPITag2 mouse model. In this mini-review, we focus on the two pharmaceuticals that have given the most interesting results in clinical trials: bevacizumab and sunitinib. These drugs are changing the management of advanced pNETs.

Epidemiological studies showed that pancreatic neuroendocrine tumors (pNETs) are rare cancers with an incidence of less than 1 per 100,000 persons per year, representing 1-2\% of all pancreatic neoplasms in Europe (1). However, in recent years, an increase of pNETs' incidence has been registered probably because of a better identification of these tumors due to the improvement of pathologic and diagnostic techniques (2). It is fundamental, in order to indicate the most appropriate therapy, a clear identification of the pNETs' origin, grading, as well as presence and localization of metastases. To date, this is possible by acquiring data from laboratory tests, histology and radiologic imaging $(3,4)$. Biopsy of the tumor is the first fundamental step to achieve an appropriate diagnosis and classification of pNET, including immunocytochemical staining to determine eventual secretion of substances ("secreting" pNETs). Thus, the first important discrimination is between well-differentiated (low or intermediate grade) or poorly differentiated (high-grade) tumors (6).

On a clinical point of view, some types of pNETs are asymptomatic and indolent and may grow at a very low rate for several years before displaying symptoms; other types can rapidly progress determining disability and worsening of quality of life (7).

If the tumor is identified in early, localized stage, radical surgery is the gold standard treatment (8). Unfortunately, hepatic 
metastases are present at diagnosis in about $10 \%$ of pNETs; approximately $85 \%$ of patients will develop hepatic metastases during a follow-up period of 20 years (9). Surgical resection of metastases is still possible in $10 \%$ of patients with liver disease with a 4-year survival rate of $73 \%$ with major hepatic resections (9) and acceptable morbidity (10). In addition to surgery, medical oncologic intervention is recommended by the most important guidelines (European Society for Medical Oncology, North American Neuroendocrine Tumor Society) in order to control hormone-dependent symptoms and to improve survival (11) (Figure 1).

Actually, in the well-differentiated, metastatic or nonresectable disease, clinical studies have demonstrated that target systemic therapies may represent a new interesting opportunity for patients with advanced pNETs (12). This review article will focus on new antiangiogenic therapies in pNETs and will highlight unresolved issues of this research area, such as choice of medications in different tumor stages, effectiveness of combination of different antiangiogenic agents, duration and scheduling of therapy and mechanism(s) of resistance. In the future, research is needed to improve the identification of the key regulators of angiogenesis in different phases of pNETs and develop a progressively personalized antiangiogenic therapy.

\section{Tumor Angiogenesis}

Angiogenesis is the development of new blood vessels from pre-existing ones; it is crucial in wound healing, embryogenesis, and normal tissue growth. However, as cancer develops through the angiogenesis process, a tumor can grow only if it is able to build new vessels from the surrounding environment (13). This process works both in local development and in metastatic spread. Notably, pNETs are highly vascularized neoplasms. This characteristic is associated to the overexpression of both ligand and related receptor of vascular endothelial factor (VEGF) (14), particularly in hepatic metastases (15). VEGF is a key driver in the metastatic process of pNETs (16) and, therefore, a pharmaceutical treatment against this pathway should be an interesting therapeutic option for patients with advanced disease. Furthermore, pNETs also show strong expression of platelet-derived growth factor receptors (PDGFRs) $\alpha$ and $\beta$, as well as stem-cell factor receptor (c-kit). Recent advances in the understanding of pNETs micro-environment biology make these receptors an interesting target for antiangiogenic treatment (17). We will focus on the role of bevacizumab and sunitinib as potential effective therapeutic options (Figure 2).

\section{Pancreatic Neuroendocrine Tumors' Medical Treatment}

PNETs represent a group of rare neoplasms that originate from pancreatic endocrine cells (18). Surgery is the gold- standard treatment in localized disease (19); when curative or radical surgery is not possible, other medical options are available with the intent to decrease tumor proliferation, slow tumor progression and control tumor symptoms. The therapeutic management is determined by many factors: histology, metastatic sites, patient's condition. Ideally, the drugs with the most appropriate pharmacological profile should be determined for each single patient. In secreting pNETs presenting with specific symptoms, the disease should be controlled using analogues of somatostatin that simulate its biological action by binding to related receptors. Somatostatin analogues (SAs), in addition to providing symptoms' control, block or slow tumor cells' proliferation, both by direct binding of specific receptors and by decreasing the availability of growth factors (20). To date, there are two synthetic SAs with proven efficacy and safety: octreotide and lanreotide $(21,22)$. The only chemotherapeutic drug with solid evidence-based medical data in advanced pNETs is streptozotocin, an alkylanting agent of the nitrosourea class of compounds, that induces damage in DNA and cell death (apoptosis and necrosis) (23). Other types of chemotherapy did not show a clear advantage compared to streptozotocin.

\section{Angiogenesis Inhibitors to Treat pNETs}

Bevacizumab. Vascular endothelial growth factor (VEGF) is a heparin-binding glycoprotein that stimulates angiogenesis in numerous tumors; it has been demonstrated that the inhibition of the VEGF pathway represents an effective antiangiogenic therapy in cancer (24). Bevacizumab is a recombinant human IgG1 monoclonal antibody that specifically binds VEGF in the bloodstream and blocks binding to its receptors expressed by tumor cells and vascular endothelial cells; it reduces the vessel density and, thus, the interstitial pressure around the tumor mass ameliorates the delivery of pharmacologically active molecules to tumor site (25). Its efficacy has been also demonstrated in an in vitro model of pNETs (26). Bevacizumab showed anti-tumor activity and efficacy both in monotherapy and in combination with interferon in metastatic renal cell carcinoma (27) or chemotherapy in metastatic colorectal cancer (28), lung (29) and breast (30) cancer, thus obtaining the approval by pharmaceutical authorities.

In neuroendocrine tumors, bevacizumab was recently tested in a phase II study in forty-five metastatic well/moderately differentiated NETs. The treatment consisted of a combination of octreotide long-acting release (LAR) $20 \mathrm{mg}$ per month intramuscularly (i.m.), capecitabine $2,000 \mathrm{mg}$ per os (p.o.) per day (metronomic scheme) and bevacizumab intravenously (i.v.) (5 mg/kg) every two weeks for 36 weeks; bevacizumab was administered until disease progression. The 


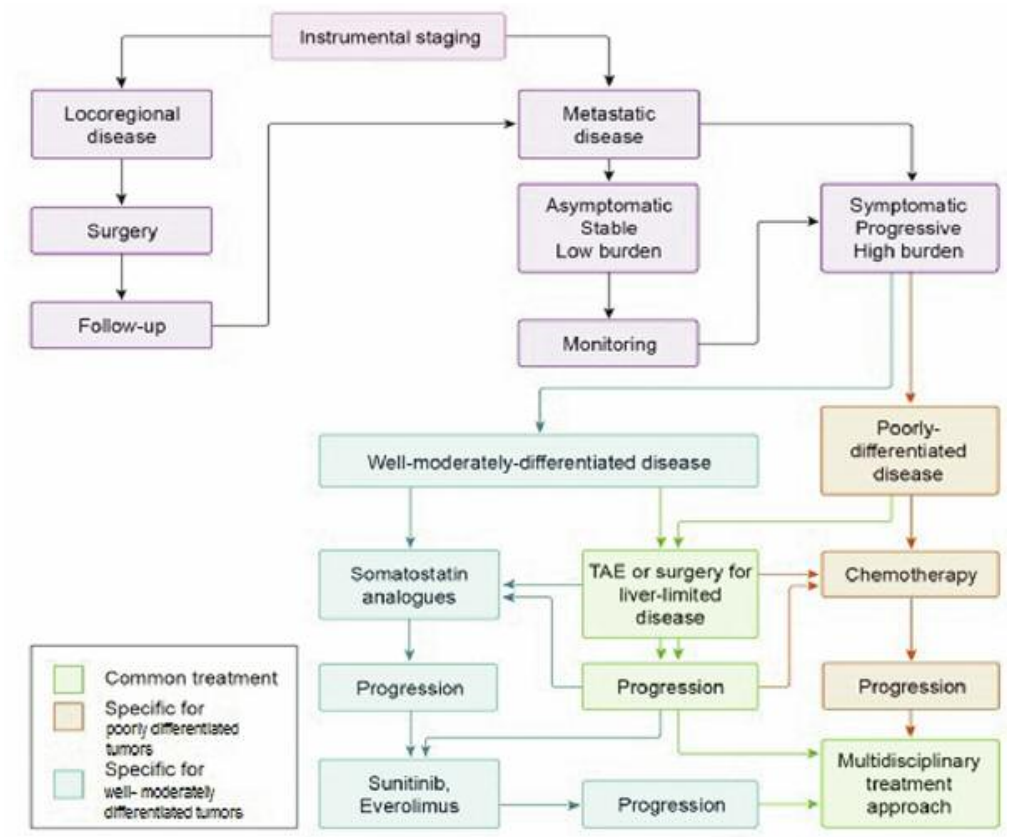

Figure 1. Management of pancreatic neuroendocrine tumors (pNETs). TAE, transcatheter arterial embolization.

treatment was well-tolerated and partial responses were observed in 8 patients (response rate: $17.8 \%$ ) with a median progression-free survival (PFS) of 14.9 months. Interestingly, the best results were obtained in pancreatic malignancies (31).

Several clinical trials are ongoing to investigate efficacy and safety of bevacizumab in association with other agents in pNETs (32). Bevacizumab was also recently tested in association with temozolomide in a phase II study. Among 34 patients enrolled, the overall response rate was $15 \%$; interestingly, responses were registered only in patients affected by pNETs, none in other carcinomas. The median PFS was 11 months: 14.3 months in pNET versus 7.3 months in other carcinomas. The median overall survival (OS) was 33.3 months: 41.7 months in pNET versus 18.8 months in other carcinomas (33). Thus, encouraging results have been obtained in selected advanced pNETs, however, in other cases, the responses were short in duration or the disease was clearly resistant. The explanation can be partially found in an important preclinical study; the VEGF-targeted molecules suppress the growth of new vessels, but the action against stable tumor vasculature was much less intense (34). Furthermore, in early phases of cancer progression, the tumor's new blood vessels are more dependent on the VEGF pathway, a dependency, however, that, in later phases, is reduced or completely lost, thus leaving space to other angiogenic drivers to gain the scene (35). In fact, other factors, such as platelet-derived growth factors (PDGFs), contribute to the angiogenic process by mediating the

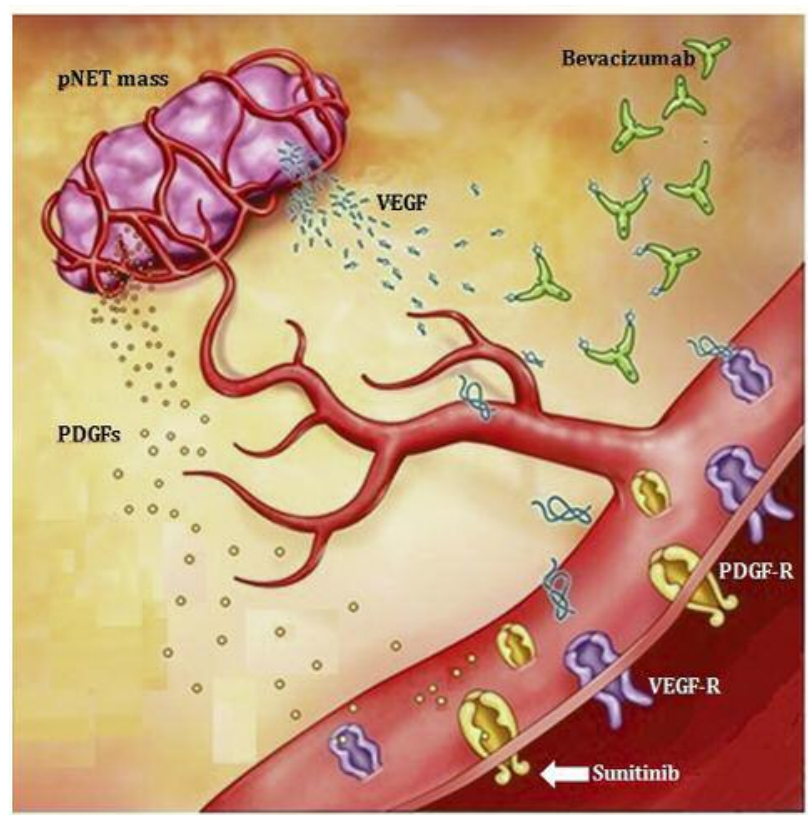

Figure 2. Bevacizumab and sunitinib inhibit the angiogenic cross-talk between pNET mass and local vasculature. Vascular endothelial growth factor (VEGF) and platelet-derived growth factors (PDGFs) are overexpressed by the pancreatic neuroendocrine tumors (pNETs) to produce new blood vessels for the growing mass; they bind to the their related receptors. Bevacizumab is a monoclonal antibody against VEGF preventing VEGF/VEGF-R interaction. Sunitinib is a small molecule that binds to and inhibits the intra-cellular tyrosine kinases' domains associated to PDGFs receptors. 
recruitment of pericytes to the neoplastic mass; the inhibition of PDGFs pathway enhances the efficacy of agents targeting VEGF (36).

Two phase III studies have been presented at ASCO 2015 (SWOG S0518 trial and the CALGB 80701 trial) but the results were disappointing. In the first trial, the association of depot octreotide with bevacizumab, in poor prognosis carcinoid patients, did not ameliorate the PFS compared to depot octreotide with interpheron alpha-2b. In the CALGB 80701 trial patients affected by metastatic pNETs were randomized to receive octreotide LAR and everolimus+/bevacizumab. Unfortunately, the association of bevacizumab with octreoide LAR did not show a significant gain in PFS.

The optimization of angiogenic therapy in pNETs is an open question; in particular, a clear clinical end-point has not been identified for bevacizumab therapy in this oncologic setting, as well as the complete spectrum of adverse events associated with its use.

Sunitinib. Sunitinib received approval for the treatment of many solid tumors (including renal cell carcinoma, gastrointestinal stromal tumors, NETs) on the basis of positive results in clinical studies $(37,38)$.

Basic research has demonstrated that many chemotherapyresistant cancer cells show hyperactivity on a plethora of tyrosine kinases, including VEGF, KIT and PDGF. Sunitinib malate is a multi-target agent able to inhibit irreversibly many tyrosine kinases overexpressed in pNETs, including VEGF receptor 2 and 3, PDGFR $\alpha$ and $\beta$, stem-cell factor receptor, showing strong antitumor properties (39).

Sunitinib was successfully tested in phase I and II studies enrolling pNETs. In a phase II study on 66 pNETs patients treated with sunitinib at $50 \mathrm{mg}$ daily for 4 weeks followed by 2 weeks of rest, a response rate of $16.7 \%$, evaluated according to RECIST criteria, was reached, with $68.2 \%$ of patients showing stable disease for over 24 weeks (40). In a further phase II study, 12 patients with advanced well-differentiated pNETs were treated with a continuous daily dose of $37.5 \mathrm{mg}$. Six patients exhibited partial response and 3 stable disease (clinical benefit 75\%, 95\% confidence interval $(\mathrm{CI})=42.8-94.5)$. In both studies, toxicity reported was consistent with the known safety profile of the drug.

In a recent multi-national, double-blind, randomized trial, the continuous schedule (sunitinib $37.5 \mathrm{mg}$ daily) was compared to placebo in 171 patients affected by advanced, well-differentiated pNETs. The study was early discontinued for the clear advantage of sunitinib versus the placebo group. Median PFS for sunitinb was 11.4 months, for placebo 5.5 months $(p<0.001)$; nine deaths occurred in the sunitinib (10\%) versus $21(25 \%)$ in the placebo group (42). Based on these results, sunitinib received approval for the treatment of locally advanced and/or metastatic pNETs.

\section{Sunitinib-Bevacizumab Association: The Clinical Results}

As sunitinib and bevacizumab block complementary angiogenic pathways, a possible therapeutic approach could be their association in order to potentiate the antitumor effects observed. A phase I exploratory study on the association between bevacizumab and sunitinib was conducted for many different malignancies (43). Interestingly, 7 out of 38 patients achieved a partial response (18\%, 95\% CI=8-34). However, grade 3 antiangiogenicspecific toxicities were observed: $47 \%$ grade 3 hypertension, $18 \%$ thrombocytopenia, $13 \%$ proteinuria.

Thus, a sequential strategy was proposed in order to reduce the toxic effects produced by their association (44). A multicenter, phase I clinical trial was conducted with sunitinib at $37.5 \mathrm{mg}$ on days $1-28$ and bevacizumab i.v. at $5 \mathrm{mg} / \mathrm{kg}$ on day 29 followed by 2 weeks of rest. Interestingly, 2 patients showed partial response, 3 stable disease. The study, however, was discontinued due to unacceptable toxicity; in fact, a patient suffered grade 1 microangiopathic hemolytic anemia; and, thus, the authors concluded that the association was nor safe neither recommendable. Furthermore, the study confirmed that, during antiangiogenic therapy with sunitinib, a compensatory production of VEGF is observed ("VEGF flare-up"). The mechanism underlying the VEGF flare-up is unknown; one of the hypotheses, however, is that VEGF could be a response of growing tumor cells and/or tumor's microenvironment to the decrease of other pro-angiogenic factors. Nevertheless, these phenomena highlight the importance of a "dynamic" evaluation of the angiogenic background of the patients during therapy.

\section{Conclusion}

The recent advances in the comprehension of pNETs' biology have prompted oncologists to investigate targeted therapies, particularly the pathways of somatostatin, VEGF and mammalian target of rapamycin. Considering the long survival of patients affected by advanced, well-differentiated neuroendocrine tumors, alternative strategies based on targeted therapies and new schedules (metronomic, alternate sequences, combinations of biologicals, etc.) are justified.

As antiangiogenic therapies limit tumors' growth and, clinically, the goal to completely cure cancer cannot be achieved, improvements of time-to-progression and/or OS appear reasonable for transforming cancer into a chronic condition. Consequently, these drugs should have a good toxicity profile and be administered on a long-term basis.

Basic research, aimed to clarify mechanisms of resistance and find markers of response, is necessary in the near future for designing more appropriate and personalized clinical trials. 


\section{Conflicts of Interest}

All Authors declare that they have no conflict of interest.

\section{Acknowledgements}

The Authors would like to thank the non-profit organization Lega Italiana Per La Lotta Contro i Tumori (LILT) of Naples, Italy.

\section{References}

1 Singh S, Asa SL, Dey C, Kennecke H, Laidley D, Law C, Asmis T, Chan D, Ezzat S, Goodwin R, Mete O, Pasieka J, Rivera J, Wong R, Segelov E and Rayson D: Diagnosis and management of gastrointestinal neuroendocrine tumors: an evidence-based Canadian consensus. Cancer Treat Rev 47: 32-45, 2016.

2 Modlin IM, Oberg K, Chung DC, Jensen RT, de Herder WW, Thakker RV, Caplin M, Delle Fave G, Kaltsas GA, Krenning EP, Moss SF, Nilsson O, Rindi G, Salazar R, Ruszniewski P and Sundin A: Gastroenteropancreatic neuroendocrine tumours. Lancet Oncol 9: 61-72, 2008.

3 Lawrence B, Gustafsson BI, Kidd M, Pavel M, Svejda B and Modlin IM: The clinical relevance of chromogranin A as a biomarker for gastroenteropancreatic neuroendocrine tumors. Endocrinol Metab Clin North Am 40: 111-134, 2011.

4 Debray MP, Geoffroy O, Laissy JP, Lebtahi R, SilbermannHoffman O, Henry-Feugeas MC, Cadiot G, Mignon M and Schouman-Claeys E: Imaging appearances of metastases from neuroendocrine tumours of the pancreas. Br J Radiol 74: 10651070, 2001.

5 Haynes CM, Sangoi AR and Pai RK: PAX8 is expressed in pancreatic well-differentiated neuroendocrine tumors and in extrapancreatic poorly differentiated neuroendocrine carcinomas in fine-needle aspiration biopsy specimens. Cancer Cytopathol 119: 193-201, 2011.

6 Kaklamanos M, Karoumpalis I, Salla C, Thomas D, Kanakis G, Alexandraki K, Sougioultzis S, Diakatou E, Kontogeorgos G and Kaltsas G: Diagnostic accuracy and clinical significance of the fine needle aspiration $\mathrm{Ki}-67$ labelling index in pancreatic endocrine tumours. Endocr Relat Cancer 18: L1-L3, 2011.

7 Hori T, Takaori K and Uemoto S: Pancreatic neuroendocrine tumor accompanied with multiple liver metastases. World $\mathrm{J}$ Hepatol 6: 596-600, 2014.

8 Fendrich V, Waldmann J, Bartsch DK and Langer P: Surgical management of pancreatic endocrine tumors. Nat Rev Clin Oncol 6: 419-428, 2009.

9 Proye C: Natural history of liver metastasis of gastroenteropancreatic neuroendocrine tumors: place for chemoembolization. World J Surg 25: 685-688, 2001.

10 Nguyen SQ, Angel LP, Divino CM, Schluender S and Warner RR: Surgery in malignant pancreatic neuroendocrine tumors. J Surg Oncol 96: 397-403, 2007.

11 Kondo NI and Ikeda Y: Practical management and treatment of pancreatic neuroendocrine tumors. Gland Surg 3: 276-283, 2014.

12 McKenna LR and Edil BH: Update on pancreatic neuroendocrine tumors. Gland Surg 3: 258-275, 2014.

13 Yadav L, Puri N, Rastogi V, Satpute P and Sharma V: Tumour angiogenesis and angiogenic inhibitors: A review. J Clin Diagn Res 9: XE01-XE05, 2015.
14 Terris B, Scoazec JY, Rubbia L, Bregeaud L, Pepper MS, Ruszniewski P, Belghiti J, Fléjou J and Degott C: Expression of vascular endothelial growth factor in digestive neuroendocrine tumours. Histopathology 32: 133-138, 1998.

15 Gomez D, Malik HZ, Al-Mukthar A, Menon KV, Toogood GJ, Lodge JP and Prasad KR: Hepatic resection for metastatic gastrointestinal and pancreatic neuroendocrine tumours: outcome and prognostic predictors. HPB (Oxford) 9: 345-351, 2007.

16 Casanovas O, Hicklin DJ, Bergers G and Hanahan D: Drug resistance by evasion of antiangiogenic targeting of VEGF signaling in late-stage pancreatic islet tumors. Cancer Cell 8: 299-309, 2005.

17 De Dosso S, Grande E, Barriuso J, Castellano D, Tabernero J and Capdevila J: The targeted therapy revolution in neuroendocrine tumors: In search of biomarkers for patient selection and response evaluation. Cancer Metastasis Rev 32: 465-477, 2013.

18 Halfdanarson TR, Rabe KG, Rubin J and Petersen GM: Pancreatic neuroendocrine tumors (PNETs): Incidence, prognosis and recent trend toward improved survival. Ann Oncol 19: 17271733, 2008.

19 Ballian N, Loeffler AG, Rajamanickam V, Norstedt PA, Weber SM and Cho CS: A simplified prognostic system for resected pancreatic neuroendocrine neoplasms. HPB (Oxford) 11: 422428, 2009.

20 Rinke A, Muller HH, Schade-Brittinger C, Klose KJ, Barth P, Wied M, Mayer C, Aminossadati B, Pape UF, Bläker M, Harder J, Arnold C, Gress T and Arnold R: Placebo-controlled, doubleblind, prospective, randomized study on the effect of octreotide LAR in the control of tumor growth in patients with metastatic neuroendocrine midgut tumors: a report from the PROMID Study Group. J Clin Oncol 27: 4656-4663, 2009.

21 Modlin IM, Pavel M, Kidd M and Gustafsson BI: Somatostatin analogues in the treatment of gastroenteropancreatic neuroendocrine (carcinoid) tumours. Aliment Pharmacol Ther 31: 169-188, 2010.

22 Oberg K, Kvols L, Caplin M, Delle Fave G, de Herder W, Rindi G, Ruszniewski P, Woltering EA and Wiedenmann B: Consensus report on the use of somatostatin analogs for the management of neuroendocrine tumors of the gastroenteropancreatic system. Ann Oncol 15: 966-973, 2004.

23 Dilz LM, Denecke T, Steffen IG, Prasad V, von Weikersthal LF, Pape UF, Wiedenmann B and Pavel M: Streptozocin/5fluorouracil chemotherapy is associated with durable response in patients with advanced pancreatic neuroendocrine tumours. Eur J Cancer 51: 1253-1262, 2015.

24 Carmeliet P and Jain RK: Molecular mechanisms and clinical applications of angiogenesis. Nature 473: 298-307, 2011.

25 Willett CG, Boucher Y, di Tomaso E, Duda DG, Munn LL, Tong RT, Chung DC, Sahani DV, Kalva SP, Kozin SV, Mino M, Cohen KS, Scadden DT, Hartford AC, Fischman AJ, Clark JW, Ryan DP, Zhu AX, Blaszkowsky LS, Chen HX, Shellito PC, Lauwers GY and Jain RK: Direct evidence that the VEGFspecific antibody bevacizumab has antivascular effects in human rectal cancer. Nat Med 10: 145-147, 2004.

26 Kasuya K, Nagakawa Y, Suzuki M, Tanaka H, Ohta H, Itoi T and Tsuchida A: Anti-vascular endothelial growth factor antibody single therapy for pancreatic neuroendocrine carcinoma exhibits a marked tumor growth-inhibitory effect. Exp Ther Med 2: 1047-1052, 2011. 
27 Harshman LC and Srinivas S: The bevacizumab experience in advanced renal cell carcinoma. Onco Targets Ther 3: 179-189, 2010.

28 Qu CY, Zheng Y, Zhou M, Zhang Y, Shen F, Cao J and Xu LM: Value of bevacizumab in treatment of colorectal cancer: A metaanalysis. World J Gastroenterol 21: 5072-5080, 2015.

29 Masago K, Fujimoto D, Fujita S, Hata A, Kaji R, Ohtsuka K, Okuda C, Takeshita $\mathrm{J}$ and Katakami N: Response to bevacizumab combination chemotherapy of malignant pleural effusions associated with non-squamous non-small-cell lung cancer. Mol Clin Oncol 3: 415-419, 2015.

30 Manso L, Moreno F, Márquez R, Castelo B, Arcediano A, Arroyo M, Ballesteros AI, Calvo I, Echarri MJ, Enrech S, Gómez A, González Del Val R, López-Miranda E, MartínAngulo M, Martínez-Jañez N, Olier C and Zamora P: Use of bevacizumab as a first-line treatment for metastatic breast cancer. Curr Oncol 22: e51-60, 2015.

31 Berruti A, Fazio N, Ferrero A, Brizzi MP, Volante M, Nobili E, Tozzi L, Bodei L, Torta M, D'Avolio A, Priola AM, Birocco N, Amoroso V, Biasco G, Papotti M and Dogliotti L: Bevacizumab plus octreotide and metronomic capecitabine in patients with metastatic well-to-moderately differentiated neuroendocrine tumors: the XELBEVOCT study. BMC Cancer 14: 184, 2014.

32 Randomized phase ii study of everolimus alone versus everolimus plus bevacizumab in patients with locally advanced or metastatic pancreatic neuroendocrine tumors (ongoing study ClinicalTrials.gov identifier NCT01229943).

33 Chan JA, Stuart K, Earle CC, Clark JW, Bhargava P, Miksad R, Blaszkowsky L, Enzinger PC, Meyerhardt JA, Zheng H, Fuchs $\mathrm{CS}$ and Kulke MH: Prospective study of bevacizumab plus temozolomide in patients with advanced neuroendocrine tumors. J Clin Oncol 30: 2963-2968, 2012.

34 Helfrich I, Scheffrahn I, Bartling S, Weis J, von Felbert V, Middleton M, Kato M, Ergün S, Augustin HG and Schadendorf $\mathrm{D}$ : Resistance to antiangiogenic therapy is directed by vascular phenotype, vessel stabilization, and maturation in malignant melanoma. J Exp Med 207: 491-503, 2010.

35 Sitohy B, Nagy JA and Dvorak HF: Anti-VEGF/VEGFR therapy for cancer: Reassessing the target. Cancer Res 72: 1909-1914, 2012.

36 Erber R, Thurnher A, Katsen AD, Groth G, Kerger H, Hammes HP, Menger MD, Ullrich A and Vajkoczy P: Combined inhibition of VEGF and PDGF signaling enforces tumor vessel regression by interfering with pericyte-mediated endothelial cell survival mechanisms. FASEB J 18: 338-340, 2004.

37 Faivre S, Demetri G, Sargent W and Raymond E: Molecular basis for sunitinib efficacy and future clinical development. Nat Rev Drug Discov 6: 734-745, 2007.
38 Faivre S, Delbaldo C, Vera K, Robert C, Lozahic S, Lassau N, Bello C, Deprimo S, Brega N, Massimini G, Armand JP, Scigalla $\mathrm{P}$ and Raymond E: Safety, pharmacokinetic, and antitumor activity of SU11248, a novel oral multitarget tyrosine kinase inhibitor, in patients with cancer. J Clin Oncol 24: 25-35, 2006.

39 Mendel D, Laird A, Xin X, Louie SG, Christensen JG, Li G, Schreck RE, Abrams TJ, Ngai TJ, Lee LB, Murray LJ, Carver J, Chan E, Moss KG, Haznedar JO, Sukbuntherng J, Blake RA, Sun L, Tang C, Miller T, Shirazian S, McMahon G and Cherrington JM: In vivo antitumor activity of SU11248, a novel tyrosine kinase inhibitor targeting vascular endothelial growth factor and platelet-derived growth factor receptors: Determination of a pharmacokinetic/pharmacodynamic relationship. Clin Cancer Res 9: 327-337, 2003.

40 Kulke MH, Lenz HJ, Meropol NJ, Posey J, Ryan DP, Picus J, Bergsland E, Stuart K, Tye L, Huang X, Li JZ, Baum CM and Fuchs CS: Activity of sunitinib in patients with advanced neuroendocrine tumors. J Clin Oncol 26: 3403-3410, 2008.

41 Okusaka T, Ito T, Nishida T, Yamao K, Igarashi H, Morizane C, Kondo S, Mizuno N, Hara K, Sawaki A, Hashigaki S, Kimura N, Murakami M, Ohki E, Chao RC and Imamura M: Phase II study of sunitinib in Japanese patients with unresectable or metastatic, well-differentiated pancreatic neuroendocrine tumor. ASCO Meeting 2012, Abstracts 30: 381.

42 Raymond E, Dahan L, Raoul J, Bang YJ, Borbath I, LombardBohas C, Valle J, Metrakos P, Smith D, Vinik A, Chen JS, Hörsch D, Hammel P, Wiedenmann B, Van Cutsem E, Patyna S, Lu DR, Blanckmeister C, Chao R and Ruszniewski P: Sunitinib malate for the treatment of pancreatic neuroendocrine tumors. $\mathrm{N}$ Engl J Med 364: 501-513, 2011.

43 Rini BI, Garcia JA, Cooney MM, Elson P, Tyler A, Beatty K, Bokar J, Mekhail T, Bukowski RM, Budd GT, Triozzi P, Borden E, Ivy P, Chen HX, Dolwati A and Dreicer R: A Phase I Study of sunitinib plus bevacizumab in advanced solid tumors. Clin Cancer Res 15: 6277-6283, 2009.

44 Bruce JY, Kolesar JM, Hammers H, Stein MN, Carmichael L, Eickhoff J, Johnston SA, Binger KA, Heideman JL, Perlman SB, Jeraj $\mathrm{R}$ and Liu G: A phase I pharmacodynamic trial of sequential sunitinib with bevacizumab in patients with renal cell carcinoma and other advanced solid malignancies. Cancer Chemother Pharmacol 73: 485-493, 2014.

Received September 1, 2016

Revised September 20, 2016

Accepted September 21, 2016 